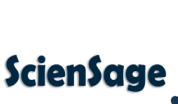

Journal of Advanced Scientific Research

Available online through https: / /sciensage.info
ISSN: 0976-9595

Research Article

DOI: $10.55218 /$ JASR. 202213116

\title{
SYNTHESIS, CHARACTERIZATION AND PHOTOCATALYTIC ACTIVITY OF NANOCRYSTALLINE LANTHANUM DOPED MOLYBDENUM OXIDE
}

\author{
Ramejabi Jahangir Sayyad, Sharda R Gadale* \\ Department of Chemistry, Yashwantrao Mohite College, Bharati Vidyapeeth (Deemed to be University), \\ Pune, Maharashtra, India \\ *Corresponding author: dagade@rediffmail.com
}

\begin{abstract}
Organic dyes effluents are a foremost source of environmental pollution and hence its removal has become an important area of research these days. A series of different concentrations of Lanthanum- Molybdenum Oxide catalysts, LMO (1\%, $5 \%, 10 \%, 15 \%$ and $20 \mathrm{wt} . \%$ ) were prepared by a sol gel method and calcined at $500^{\circ} \mathrm{C}$. Thus, synthesized LMO catalysts were characterized by Powder X-ray diffraction analysis (XRD), Flame Emission scanning electron microscopy (FESEM,) Energy-dispersed X-ray analysis (EDX), RAMAN Spectroscopy and Thermo-gravimetric analysis (TGA). The photocatalytic properties of LMO nanoparticles were investigated via methyl orange (MO) and bromothymol blue (BTB) as a model organic compound in aqueous solution under visible light irradiation. More than $80 \%$ and $60 \%$ degradation of MO and BTB dye within 150 minutes indicating the excellent photocatalytic activity of as prepared catalysts.
\end{abstract}

Keywords: Organic dyes effluents, Lanthanum-Molybdenum Oxide, Photocatalytic, Sol-gel, nanoparticles, Degradation.

\section{INTRODUCTION}

In the last few decades contamination of potable water streams has increased enormously due to increased population and global industrialization. Mainly industries like textiles, printing, dyeing, paper, and plastic produces dye effluents which can contaminate the freshwater supply [1-2]. These dyes are harmful to human organs viz. liver, kidneys and nervous system [34]. The bright colours of dyes cause a barrier to the penetration of oxygen and sunlight into natural water bodies affecting the aquatic life. Their adverse effects on the environment are alarming hence it is necessary to degrade them before discharging them to aquatic environments. A number of physical, chemical, and biological methods are available for the treatment of coloured waters. Conventional methods of water treatment include oxidation process [5], adsorption [68], reverse osmosis [9], coagulation [10-11]. Among the advanced oxidation processes (AOPs), heterogeneous photocatalysis has attracted considerable attention for the degradation of organic pollutants in water and air [12-13]. Photo-assisted processes are clean, safe, efficient and low-cost. Photocatalytic dye degradation method is a combination of two processes. Initially, there is adsorption of dye molecules on the catalysts surface and advanced oxidation process by the formation of free radicals due to the light irradiation.

Now-a-days, extensive attention has been paid to the transition metal oxide (TMO) based nanomaterials as catalysts due to suitable electronic, optical, thermal, chemical, and mechanical properties. The most commonly used transition metals for this purpose are iron [14-15], copper [16], vanadium [17-18], cobalt [19], molybdenum [20] and manganese [21]. Up to now, lanthanide ions have been considered to be the ideal cocatalyst materials, because they can form complexes with various Lewis bases (e.g., acids, amines, aldehydes, alcohols, thiols) through interactions of these functional groups with the ' $\mathrm{f}$ ' orbitals of the lanthanides. [22-23]. It is widely acknowledged that the presence of $\mathrm{La}$ stimulates electron trapping and therefore limits their recombination with holes to prevent the formation of electron-hole pairs. This leads to improve the photodegradation efficiency [24-25]. L. Yao, Z. Chen, J. Li, et al. reported effective photodegradation of methyl orange dye using lanthanum-doped bismuth titanate nanosheets [26]. Ruhollah Talebi et.al. synthesised lanthanum doped zinc ferrite nanoparticles by sol-gel method for 
degradation of methyl orange under ultraviolet light irradiation [27]. Photocatalytic degradation of an azo dye using $\mathrm{Bi}_{3.25} \mathrm{M}_{0.75} \mathrm{~T}_{\mathrm{i} 3} \mathrm{O}_{12}$ nanowires $(\mathrm{M}=\mathrm{La}, \mathrm{Sm}, \mathrm{Nd}$, and $\mathrm{Eu}$ ) reported by Xue Lina et al, for methyl orange degradation [28]. A novel lanthanum inserted $\mathrm{CuCr}_{2} \mathrm{O}_{4}$ nanoparticles have been designed and developed for the efficient removal of water pollutions by Hamed Ramezanalizadeha et al. [29]. $\mathrm{Eu}^{2+}$ doped lanthanummagnesium-gallium $/ \mathrm{TiO}_{2}$-based composition have been successfully studied as photocatalytic materials for cement concrete-related methyl orange degradation by Jian Zhanga [30]. Loan T. T. Nguyen et al. synthesised La-doped Zinc Oxide nano-particles for effective degradation of methyl orange [31].

To the best of our knowledge, there has not been any report on the synthesis of LMO catalyst for the degradation of methyl orange and bromothymol blue. Therefore, we have synthesized LMO catalyst with a uniform morphology and good structural stability by sol gel method. Thus, prepared catalysts were calcined at $500^{\circ} \mathrm{C}$ and characterized using standard analytical techniques. The photocatalytic activities of the synthesized material were tested for the degradation of methyl orange and bromothymol blue under visible light illumination.

\section{MATERIAL AND METHODS}

\subsection{Material}

All the chemicals used in this study were of analytical grade. Lanthanum nitrate, Ammonium heptamolybdate, Ammonium hydroxide solution, isopropyl alcohol, Methyl Orange and distilled water were obtained from Merck chemicals, India.

$\mathrm{X}$-ray diffraction (XRD) analysis was done at room temperature using Rigaku, Miniflex G-600 diffractometer. Flame ionization Scanning electron microscope (FE SEM) measurement was performed on (Nova Nano SEM NPEP303). The elemental compositions were analyzed by SEM associated energy-dispersed X-ray microanalysis (EDX) operated with the beam energy of $15 \mathrm{kV}$. Thermogravimetric analysis (TGA) was performed on Perkin Elmer TGA7 under nitrogen between $25^{\circ} \mathrm{C}$ to $850^{\circ} \mathrm{C}$ at a constant heating rate of $20^{\circ} \mathrm{C} / \mathrm{min}$. Raman spectra were acquired at room temperature by using Laser Raman spectrometer (HR800-UV confocal micro-Raman Spectrometer).

\subsection{Preparation of $\mathrm{La}_{2} \mathrm{O}_{3} / \mathrm{MoO}_{3}$ Photocatalyst}

Lanthanum doped on $\mathrm{MoO}_{3}$ Oxide (LMO) photocatalysts were prepared with varying wt. \% of Lanthanum oxide concentration $(1,5,10,15$, and 20 wt. \%) in a typical procedure. The $10 \mathrm{wt}$ \% LM catalyst was synthesized by dissolving equimolar quantity of Lanthanum nitrate in 20 $\mathrm{ml}$ distilled water in sonicator for $30 \mathrm{~min}$. This solution was added drop wise to the Ammonium heptamolybdate (AHM) solution with constant stirring. To this mixture, aqueous solution of ammonium hydroxide was added. The resultant transparent bluish gel was obtained, further air dried for overnight and then heated in oven at $100^{\circ} \mathrm{C}$ for 10 hours. Dried catalyst was calcined at $500^{\circ} \mathrm{C}$ for 04 hours. Similarly, catalysts with 1, 5, 15, and 20 wt. \% LMO were prepared.

\subsection{Photocatalytic activity studies}

The effect of the presence of the nanoparticles on the photodegradation of $\mathrm{MO}$ and $\mathrm{BTB}$ dye was evaluated under visible light irradiation. The solution of $10 \mathrm{mg}$ of dye powder in $100 \mathrm{ml}$ distilled water was prepared. About $0.2 \mathrm{gm}$ of LMO catalysts was added to $50 \mathrm{ml}$ of Dye solution. To develop equilibrium between the catalyst and substrate, the suspension was stirred for 60 min in dark prior exposing to visible light. After that the suspension was irradiated with visible light at constant stirring. $3 \mathrm{~mL}$ of the suspension was taken regularly from the reactor at different irradiation time intervals. The catalytic performance of the catalyst was analyzed quantitatively for the absorption peak at $470 \mathrm{~nm}$ of $\mathrm{MO}$ and $600 \mathrm{~nm}$ of BTB in aqueous heterogeneous solution suspensions. The following formula was used to calculate the percentage of dye degradation.

Degradation Efficiency $=\left\{\left(\mathrm{C}_{0}-\mathrm{C}_{\mathrm{t}}\right) / \mathrm{C}_{0}\right\} \times 100 \quad$ Eq. (1) Where $\mathrm{C}_{0}$ is the initial concentration of the dye solution, $\mathrm{C}_{\mathrm{t}}$ is the concentration of the dye solution after photo irradiation in a selected time interval.

\section{RESULTS AND DISCUSSION}

\subsection{XRD analysis}

XRD measurement of the samples was carried out for understanding the structural property as well as other information related to the crystal size of the prepared nanophotocatalyst of various amount of $(1,5,10,15$ and 20 wt. \%) $\mathrm{La}_{2} \mathrm{O}_{3}$ doped on $\mathrm{MoO}_{3}$ were investigated by Xray diffraction studies over the $2 \theta$ values in the range of $10-80^{\circ}$. The powdered samples calcined at $500^{\circ} \mathrm{C}(4 \mathrm{~h})$ showed slight crystalline nature. It showed lanthanum molybdenum oxide and dilanthanum tetramolybdate two phases with the diffraction peaks $17.55^{\circ}, 21.50^{\circ}, 24.88^{\circ}$, $27.87^{\circ}, 37.61^{\circ}, 39.84^{\circ}, 41.85^{\circ}, 47.58^{\circ}, 52.71^{\circ}$, $66.57^{\circ}, 70.93^{\circ}$ for lanthanum molybdenum oxide phase $\left(\mathrm{La}_{2} \mathrm{Mo}_{2} \mathrm{O}_{9}\right)$ (ICDD,PDF2DBcard.no.00-061-0510) and 
$12.75^{\circ}, 25.82^{\circ}, 27.35^{\circ}, 29.64^{\circ}, 33.74^{\circ}, 35.43^{\circ}, 38$. $90^{\circ}, 39.62^{\circ}, 45.76^{\circ}, 46.21^{\circ}, 49.24^{\circ}, 52.79^{\circ}, 56.37^{\circ}$, $64.48^{\circ}, 69.49^{\circ}, 76.53^{\circ}, 78.76^{\circ}$ for Molybdenum oxide $\left(\mathrm{MoO}_{3}\right)$.(ICDD, PDF2DB card.no.01-076-2710). The crystallite size in the range of $11.8 \mathrm{~nm}$ to $60 \mathrm{~nm}$ was calculated from the Debye Scherrer equation $(D=0.9 \lambda / \beta$ $\cos \theta)$, where $D$ is the crystal size, $\lambda$ is the wavelength of $\mathrm{X}$-ray, $\theta$ is the Braggs angle in radians, and $\beta$ is the full width at half maximum of the peak in radians.

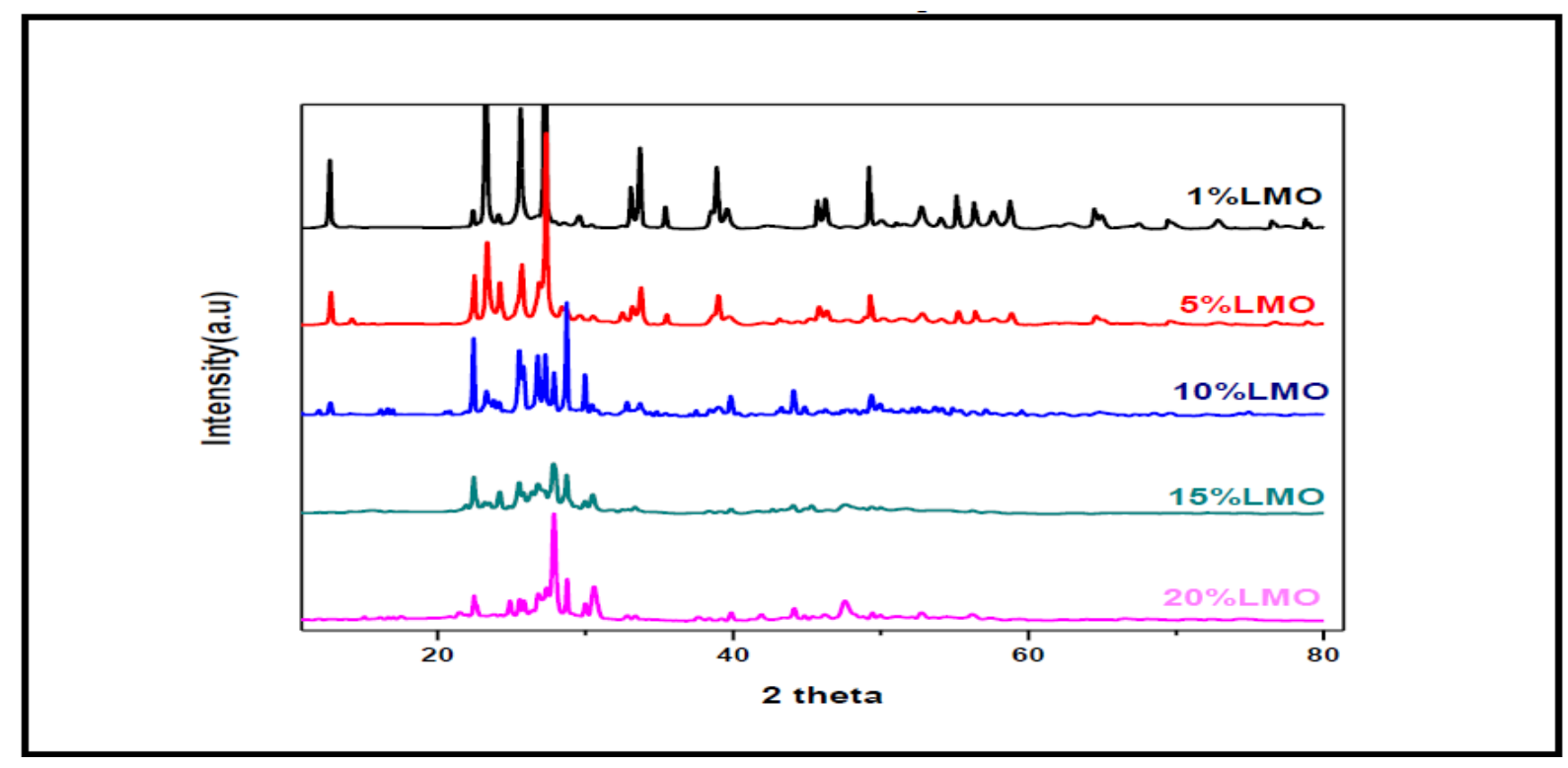

Fig. 1: X-ray diffraction pattern ofLa $\mathrm{O}_{3} / \mathrm{MoO}_{3}$ (LMO) $1 \%, 5 \%, 10 \%, 15 \%$ and $20 \mathrm{wt} . \%$ catalyst calcined at $500^{\circ} \mathrm{C}$

\subsection{EDX-SEM}

The chemical composition of resulting LMO catalyst has been analyzed by EDX and shown in fig. 2(a,b). In the EDX spectra, the signals of La, Mo and O elements are clearly observed which confirmed the composition of the catalyst.

The surface morphology of the LMO catalysts were investigated by FESEM microscopy. Fig. 3 showed the FESEM images of LMO catalyst, the results showed a sharp-edge plate-like morphology with agglomeration also presence of separate particles of a small size along with large aggregates.

\subsection{TGA Analysis}

Thermo-gravimetric analysis of uncalcined catalyst purified from the reaction mixture was performed under air to discover the processes occurring during the thermal treatment (Fig. 4). The first weight loss up to $100^{\circ} \mathrm{C}$ was assigned to the desorption of remaining ethanol and possibly water present in the sample as a result of the purification steps. Next, the heating step led to a quite clear decomposition of the organic components occurring with maximal speed at 100 $160^{\circ} \mathrm{C}$ and completing when the temperature reached $240^{\circ} \mathrm{C}$ This is a characteristic temperature regime for the decomposition of remaining alkoxide groups, and the resulting product is a completely amorphous oxide [32].

This step is also typically associated with formation of residual graphitic carbon. The next step occurs between $240^{\circ} \mathrm{C}$ and about $320^{\circ} \mathrm{C}$. It most likely corresponds to the combustion of the graphitic carbon on the surface of the oxide aggregates and the first transformation in their morphology associated with the partial crystallization of the reduced phases. The two following steps were then, in turn, associated with further structural transformation of the oxide material with deeper and deeper exposure and combustion of the residual carbon. The last sharply defined step in weight loss took place after $320^{\circ} \mathrm{C}$ and finished around $480^{\circ} \mathrm{C}$. Under these conditions, the molybdenum cations were finally oxidized completely into $\mathrm{Mo}^{6+}$, and the material turned fully crystalline and carbon free. Further, slow weight loss is associated with a noticeable minor loss of $\mathrm{Mo}^{4+}$ in the form of the volatile $\mathrm{MoO}_{3}$ under these conditions, which can lead to a slight sub stoichiometry of the produced phases in relation to Mo. 


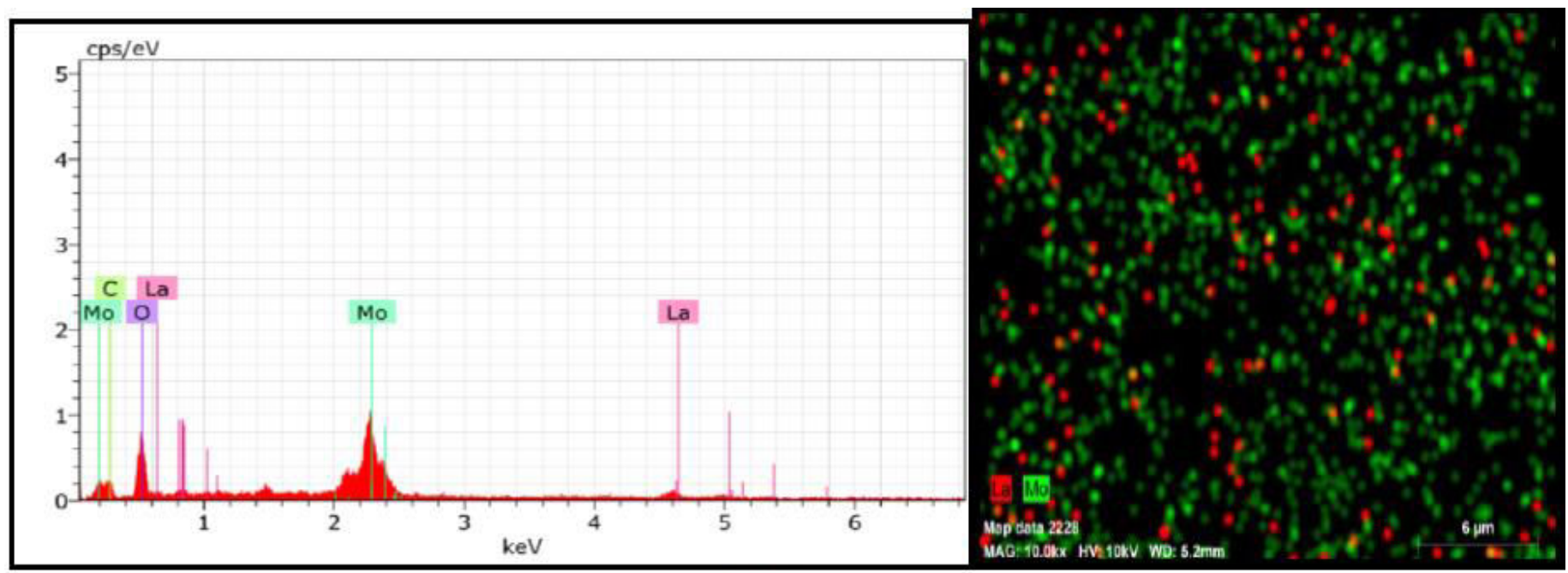

(a)

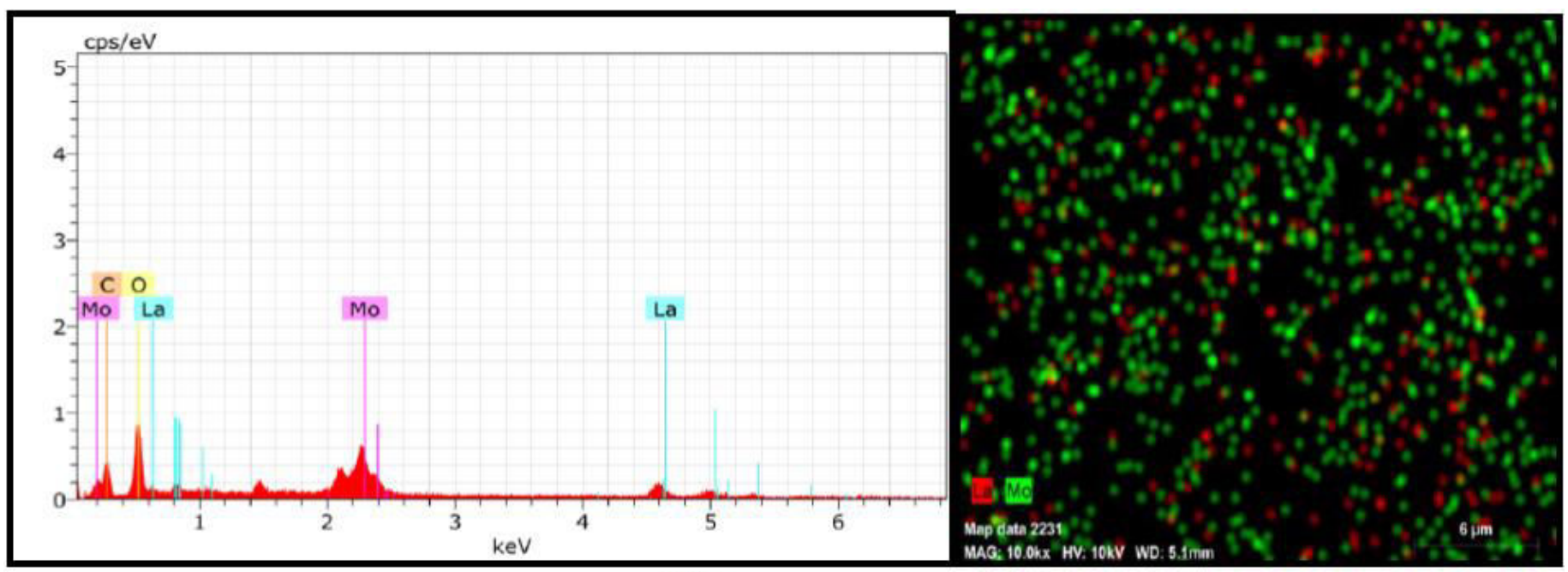

(b)

Fig. 2: EDX spectrum of representative samples of $\mathrm{La}_{2} \mathrm{O}_{3} / \mathrm{MoO}_{3}$ (LMO) catalyst.

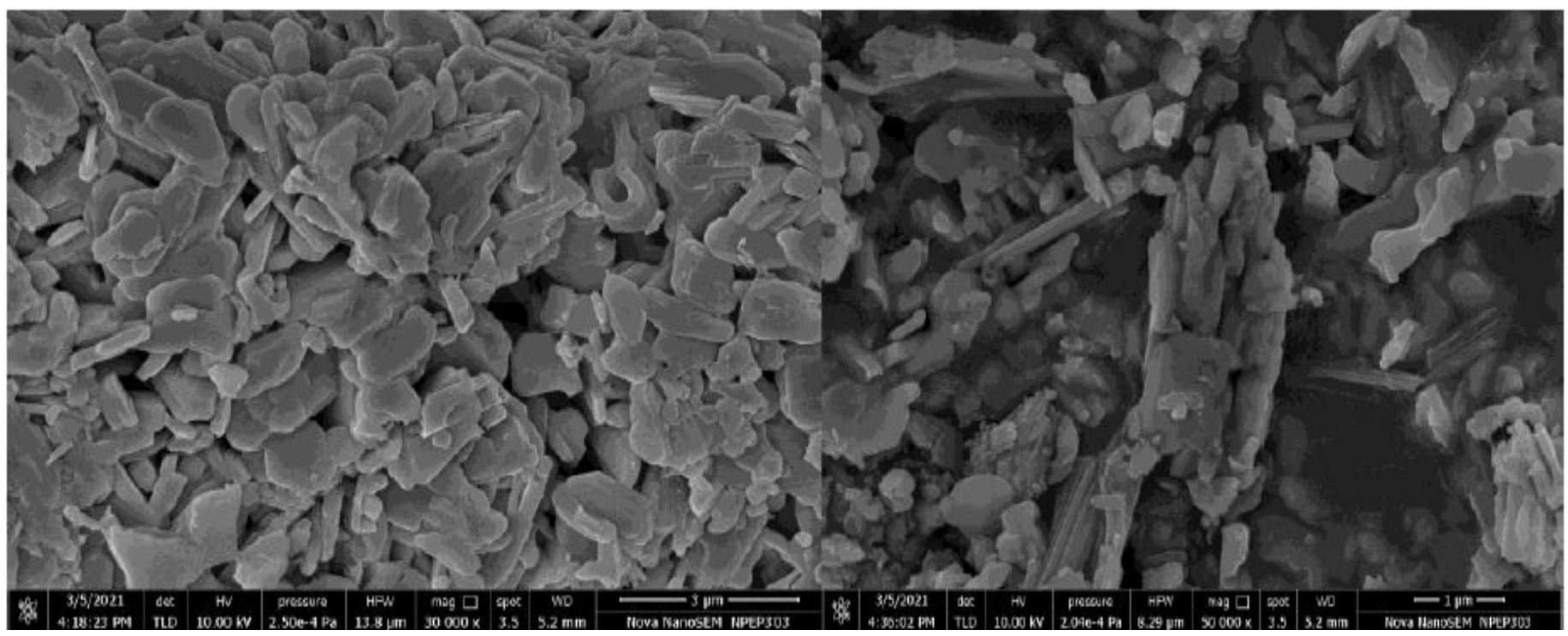

(a)

(b) 


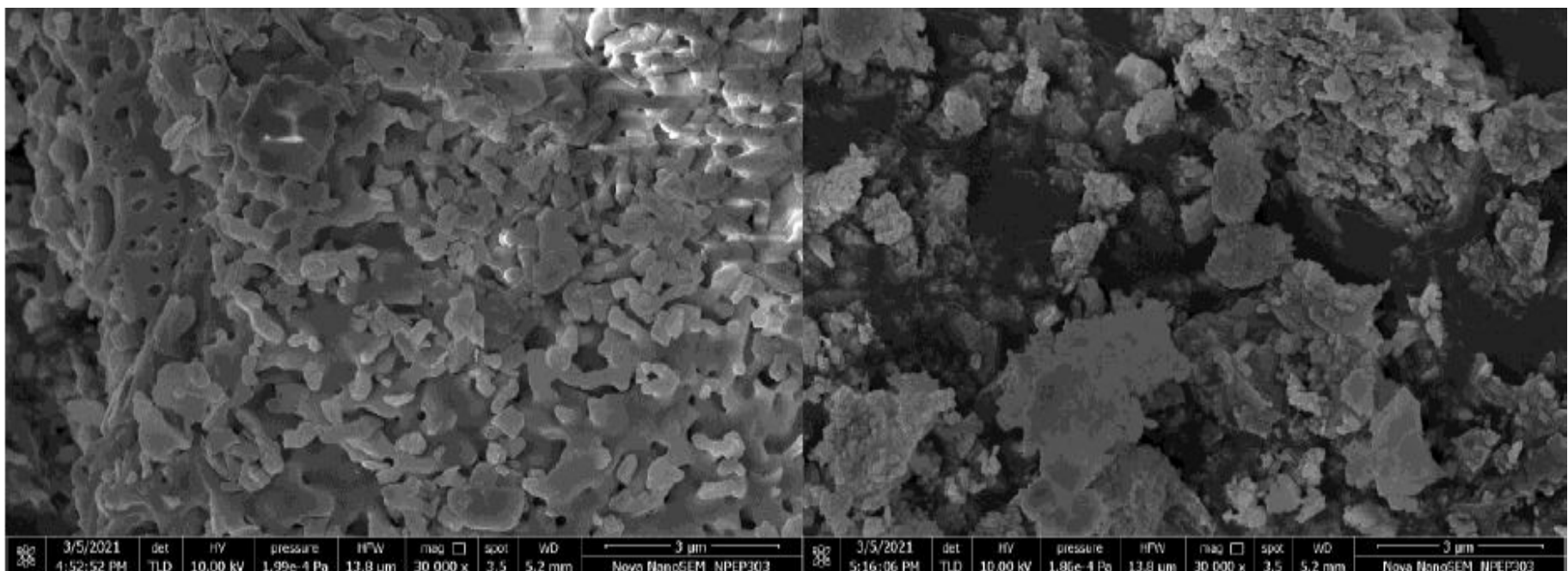

(c)

(d)

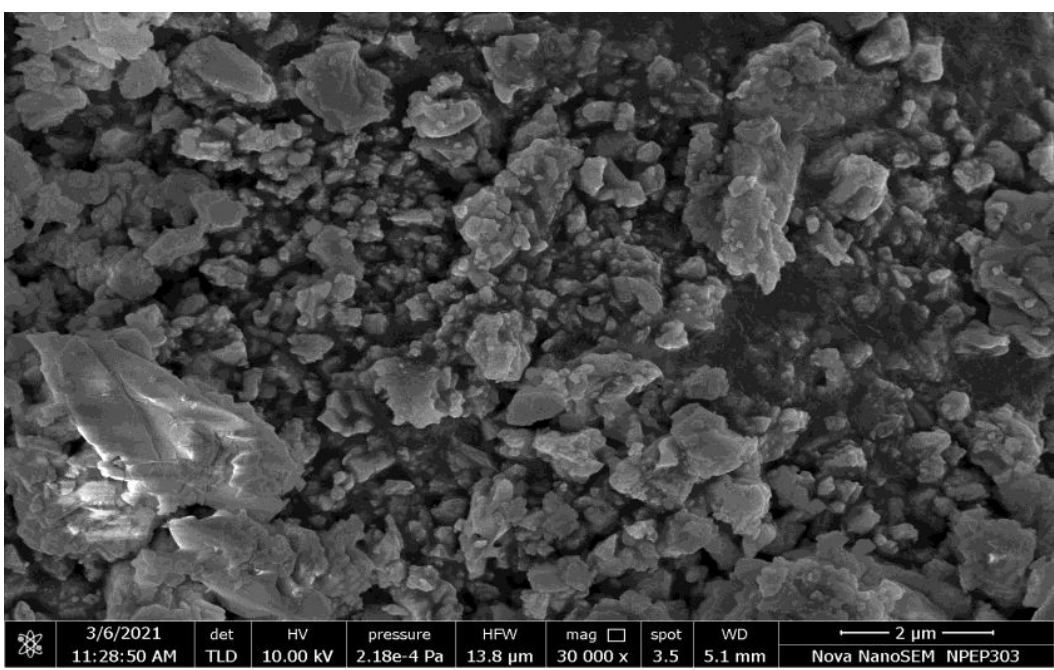

(e)

Fig. 3: FE-SEM Images of (a)1\% LMO, (b) 5\%LMO, (c)10\% LMO, (d)15\%LMO, (e) 20\%LMO catalyst

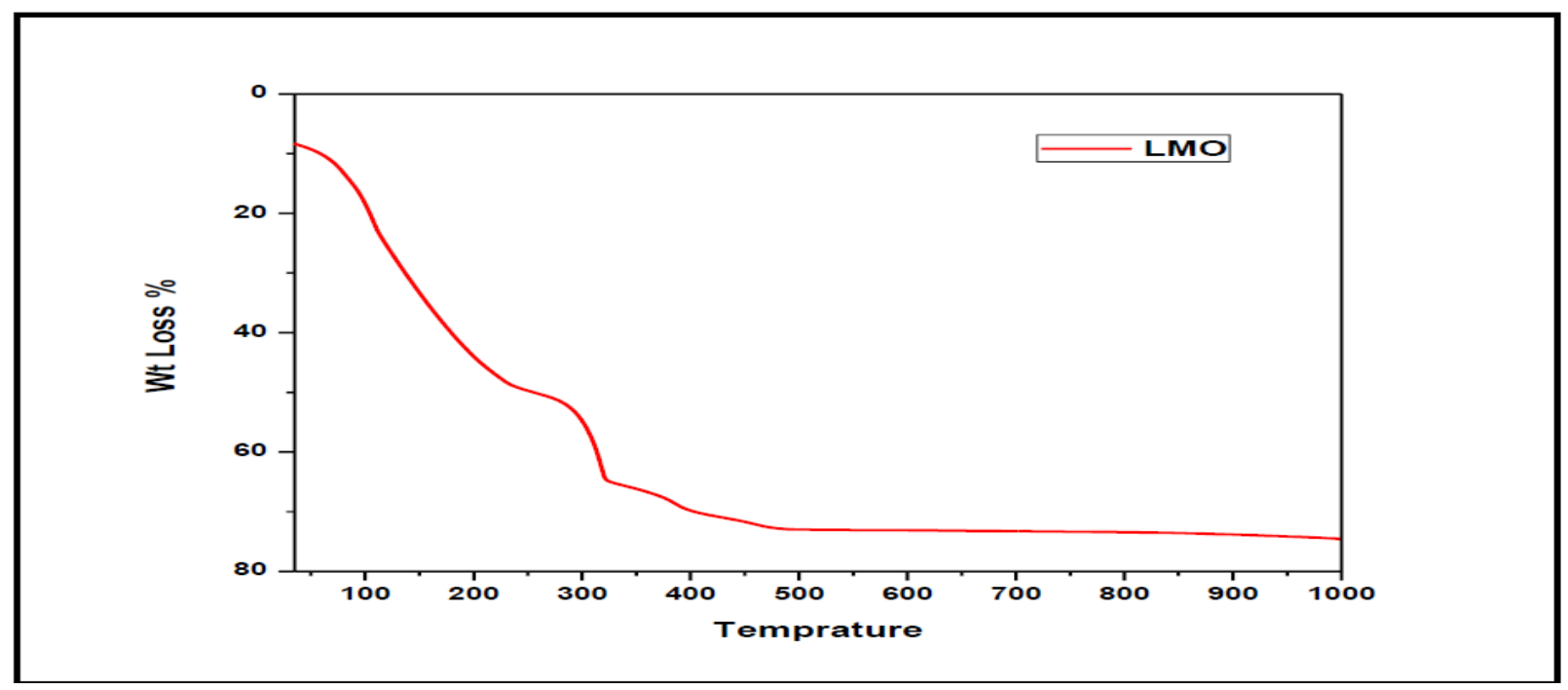

Fig. 4: TGA analysis of the Uncalcined sample of LMO 


\subsection{Raman Analysis}

This technique is widely employed to identify molecules and study of chemical bond between oxide as well as supported oxide catalysts. Vibrational frequencies are specific to chemical bond and symmetry of molecules. Raman spectroscopic analysis after calcinations allowed us to possess a more insight of actual nature of deposited Lanthanum and oxy-molybdenum species. The Raman spectra were recorded for $\mathrm{La}_{2} \mathrm{O}_{3} / \mathrm{MoO}_{3}$ and various wt. $\% \mathrm{La}$ on $\mathrm{MoO}_{3}(\mathrm{LMO})$ catalysts calcined at $500^{\circ} \mathrm{C}$ and shown in the fig. 5 . The Lanthanum molybdenum oxide (LMO) samples showed peaks for La-Mo interaction. The spectra showed peaks of $\alpha-\mathrm{MoO}_{3}$ at $\sim 159,286$, 336, 379, 666, 821 and $997 \mathrm{~cm}^{-1}$ which matched with literature [33]. The presence of intense peak at 997, 666 $\mathrm{cm}^{-1}$ which indicated $\mathrm{V} \mathrm{Mo}=\mathrm{O}$ terminal stretching mode, the symmetric and asymmetric stretching modes of the Mo-O-Mo bridges in $\alpha-\mathrm{MoO}_{3}$. The band present at $275 \mathrm{~cm}^{-1}$ which attributed to $v$ Mo-O-Mo deformation mode corresponds to LMO catalyst. As increasing the concentration of La loading, new Raman lines appear at 934, $953 \mathrm{~cm}^{-1}$, the exact origin of which was not clearly seen. However, these peaks were not appeared in 1\% LMO spectra, At higher La oxide loading, from $5 \%$ to $20 \% \mathrm{La}$, Raman spectra exhibit the characteristic lines of $\mathrm{La}_{2} \mathrm{O}_{3}\left(934,953 \mathrm{~cm}^{-1}\right)$. The presence of $821 \mathrm{~cm}^{-1}$ indicated $\mathrm{MoO}_{3}$ band. The presence of Mo-O-Mo stretching and deformation mode showed at 666 and $286 \mathrm{~cm}^{-1}$.

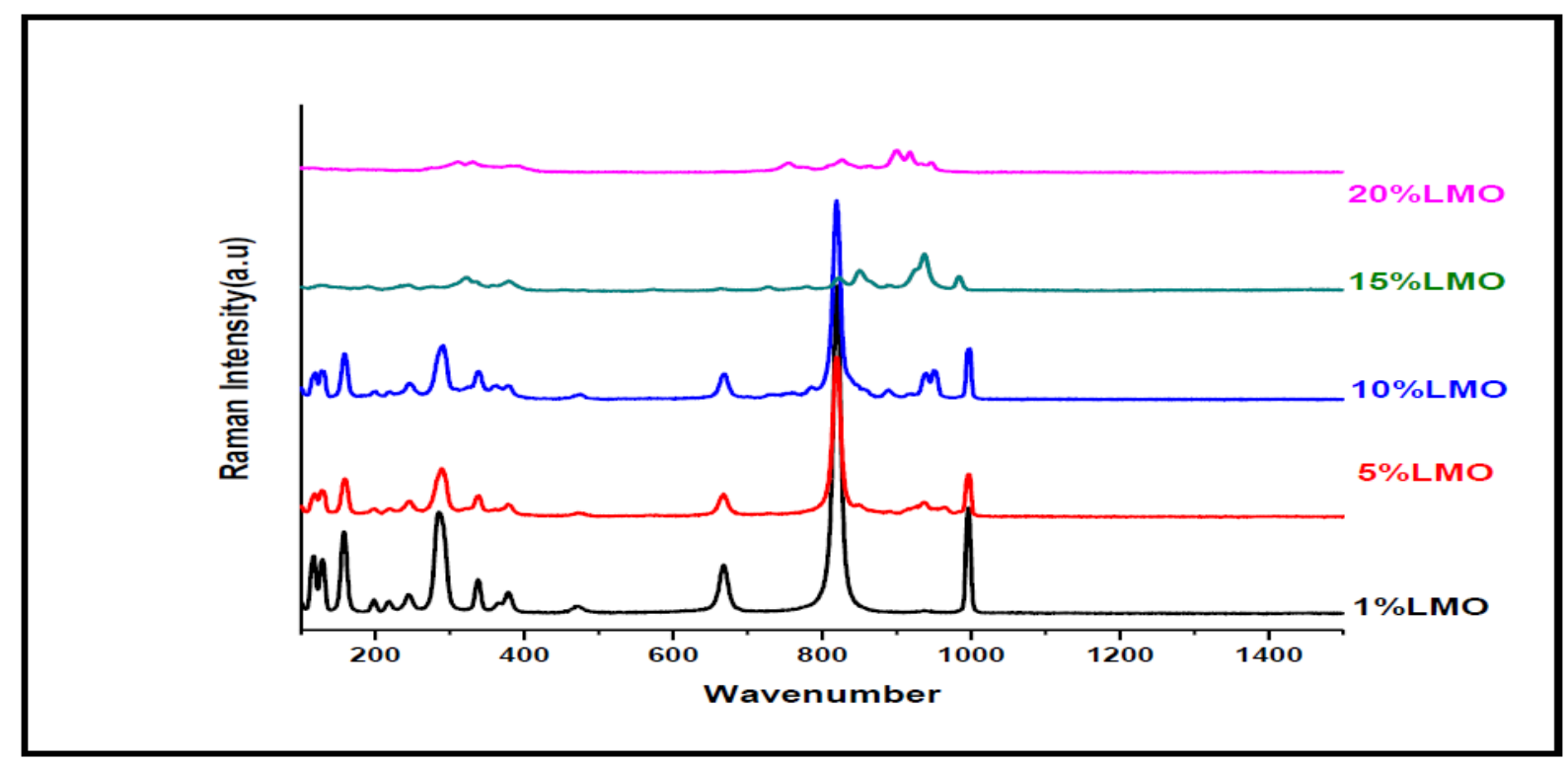

Fig. 5: RAMAN analysis of the sample of $L M O$ at $500^{\circ} \mathrm{C}$

\subsection{Photocatalytic reduction of $\mathrm{MO}$}

In a typical photodegradation of organic pollutants process, the generation of electron hole pairs by visible light irradiation produces $\mathrm{O}_{2}$ and $\mathrm{OH}$ radicals. These highly active radicals start degrading the organic pollutants present in the water solution and in turn reduce to harmless by-products $\left(\mathrm{CO}_{2}\right.$ and $\left.\mathrm{H}_{2} \mathrm{O}\right)$. Large surfaces may possibly have many active sites, which might increase the possibility of maximum interactions between the dye molecules and the nano catalyst. Once the process starts, the superoxide anion radicals $\cdot \mathrm{O}_{2}$ can be produced, and meanwhile, $\bullet \mathrm{OH}$ - radicals can be produced by the reaction of $\mathrm{OH}$ - with holes.

As the electrons react with the catalyst, the $\mathrm{H}_{2} \mathrm{O}$ molecules are converted into $\mathrm{OH}$. The radicals produced in the process, that is, $\bullet \mathrm{O}_{2}$ - and $\bullet \mathrm{OH}_{-}$, being highly reactive for the organic pollutants degrade it to the harmless by-products that are $\mathrm{CO}_{2}$ and $\mathrm{H}_{2} \mathrm{O}$. The mechanism of degradation is given by the equations below

$$
\begin{aligned}
& \mathrm{LMO}+\text { Light energy (hv) } \rightarrow \mathrm{LMO}+\mathrm{e}^{-}+\mathrm{h}^{+} \\
& \mathrm{e}^{-}+\mathrm{O}_{2} \rightarrow \cdot \mathrm{O}_{2}^{-} \\
& \mathrm{h}^{+}+\mathrm{H}_{2} \mathrm{O} \rightarrow \cdot \mathrm{OH}^{-} \\
& \mathrm{MO}+\cdot \mathrm{OH}^{-} \rightarrow \mathrm{CO}_{2}+\mathrm{H}_{2} \mathrm{O} \text { (degradation byproducts) } \\
& \mathrm{MO}+\cdot \mathrm{O}_{2}^{-} \rightarrow \mathrm{CO}_{2}+\mathrm{H}_{2} \mathrm{O} \text { (degradation byproducts) }
\end{aligned}
$$

The photocatalytic activities of the LMO photocatalyst were evaluated by photodegradation of aqueous solution of MO and BTB dyes under visible-light irradiation. Fig. 6 represents absorbance spectra recorded from 300 to 
$650 \mathrm{~nm}$ for MO dye under regular interval of time. LMO as photocatalyst plays a vital role for photodegradation application, which is mainly due to adsorption of dye molecules. Decrease in absorbance intensity clearly confirms that LMO are acting as photocatalyst for the degradation of dye. Fig. 7 shows a corresponding plot between degradation efficiency and irradiation time by varying LMO concentration. These results clearly showed that 20\% LMO was optimum concentration which has degraded concentration of dye by $88.22 \%$ within $150 \mathrm{~min}$. Similarly, Fig. 8 represents absorbance spectra recorded from 300 to $650 \mathrm{~nm}$ for BTB dye under regular interval of time and Fig. 9 shows a corresponding plot between degradation efficiency and irradiation time for BTB by different LMO catalysts. In this case 20\% LMO showed 65.13\% degradation within 150 minand no more degradation occurs after wards $150 \mathrm{~min}$.

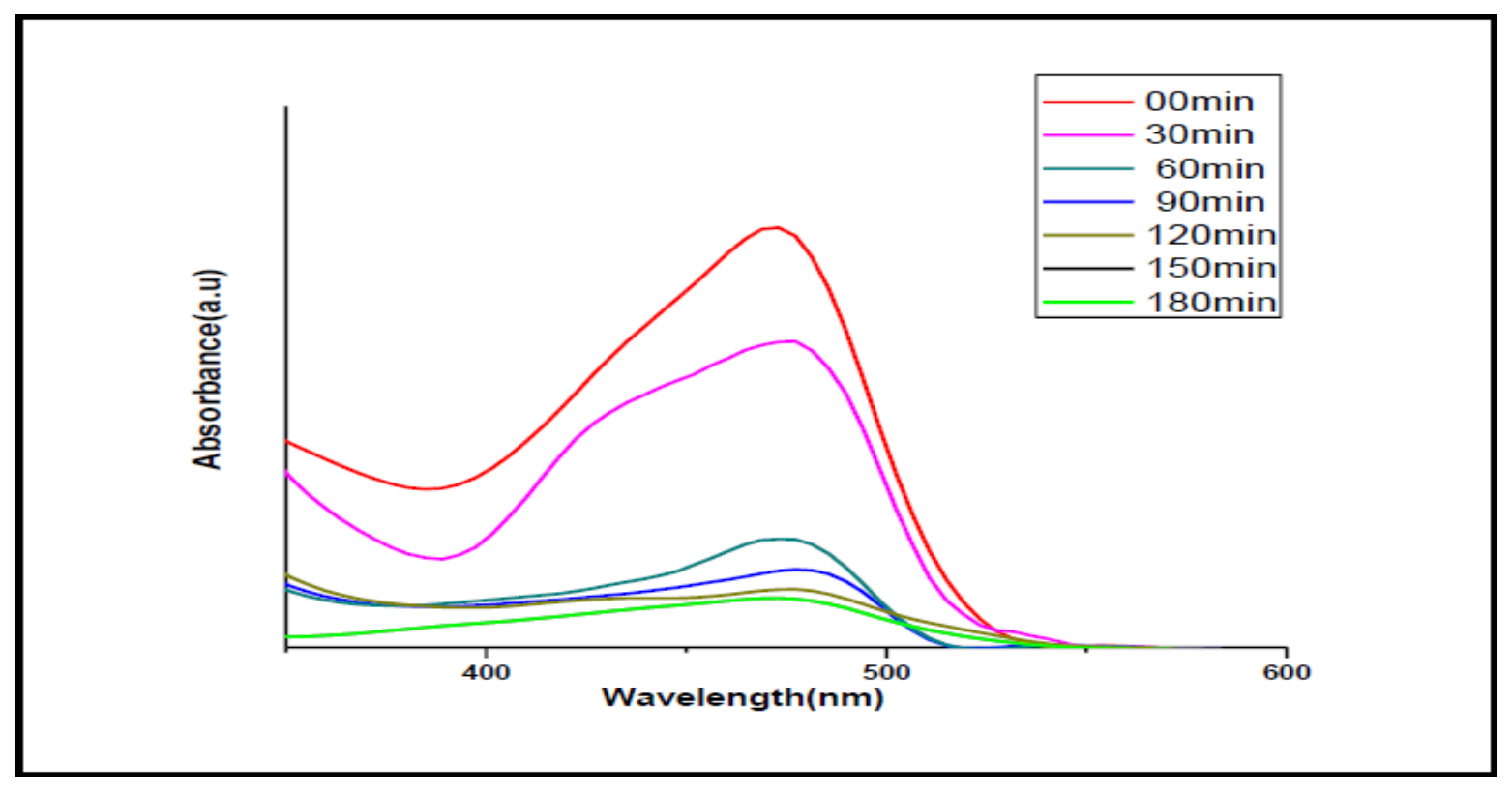

Fig. 6: UV-visible spectra of MO degradation using LMO Catalyst

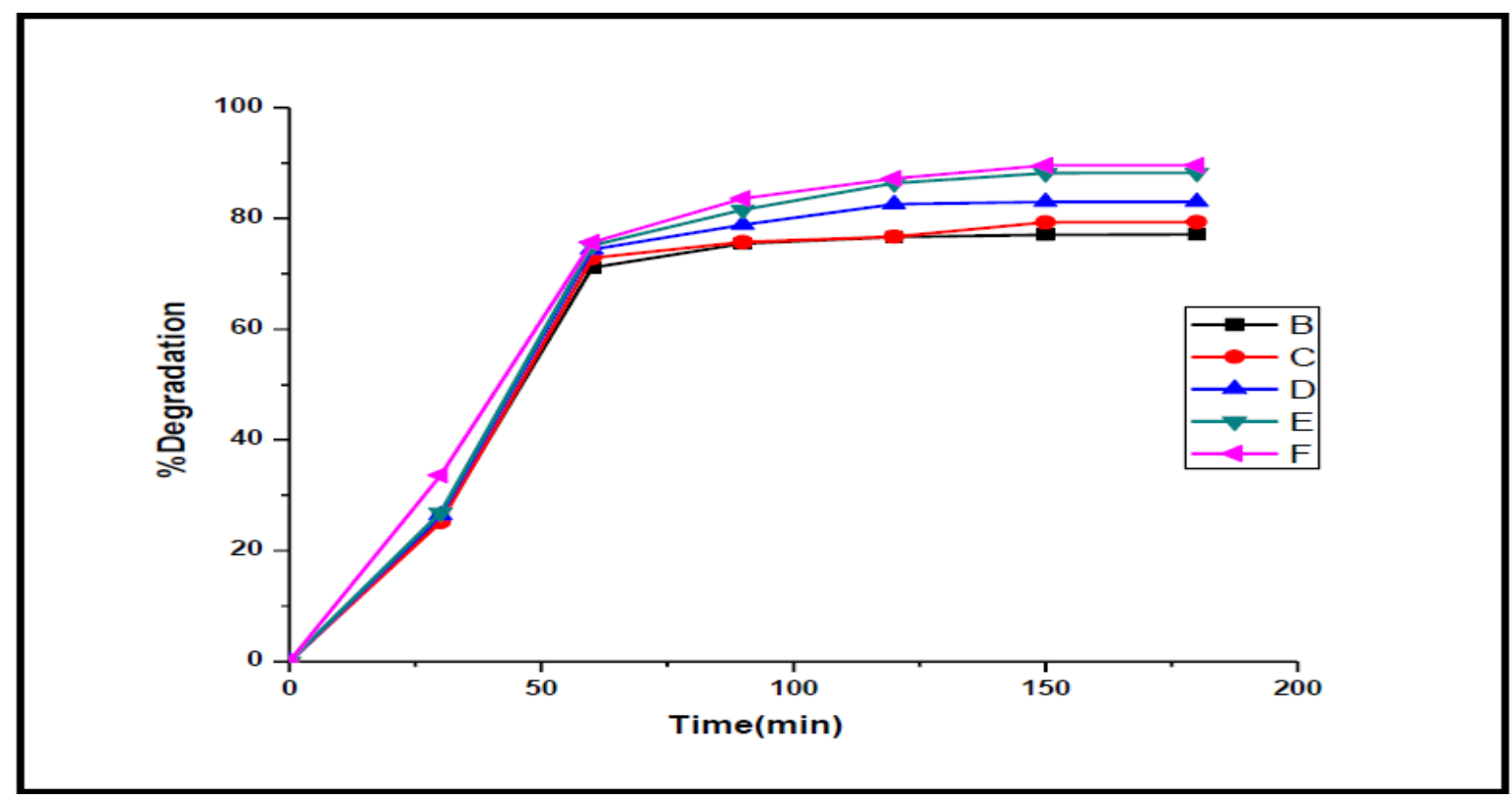

Fig. 7: Photodegradation of MO usingLMO catalyst (B), 1\%LMO, (C) 5\%LMO, (D) 10\%LMO, (E) 15\% LMO, (F) 20\% LMO 


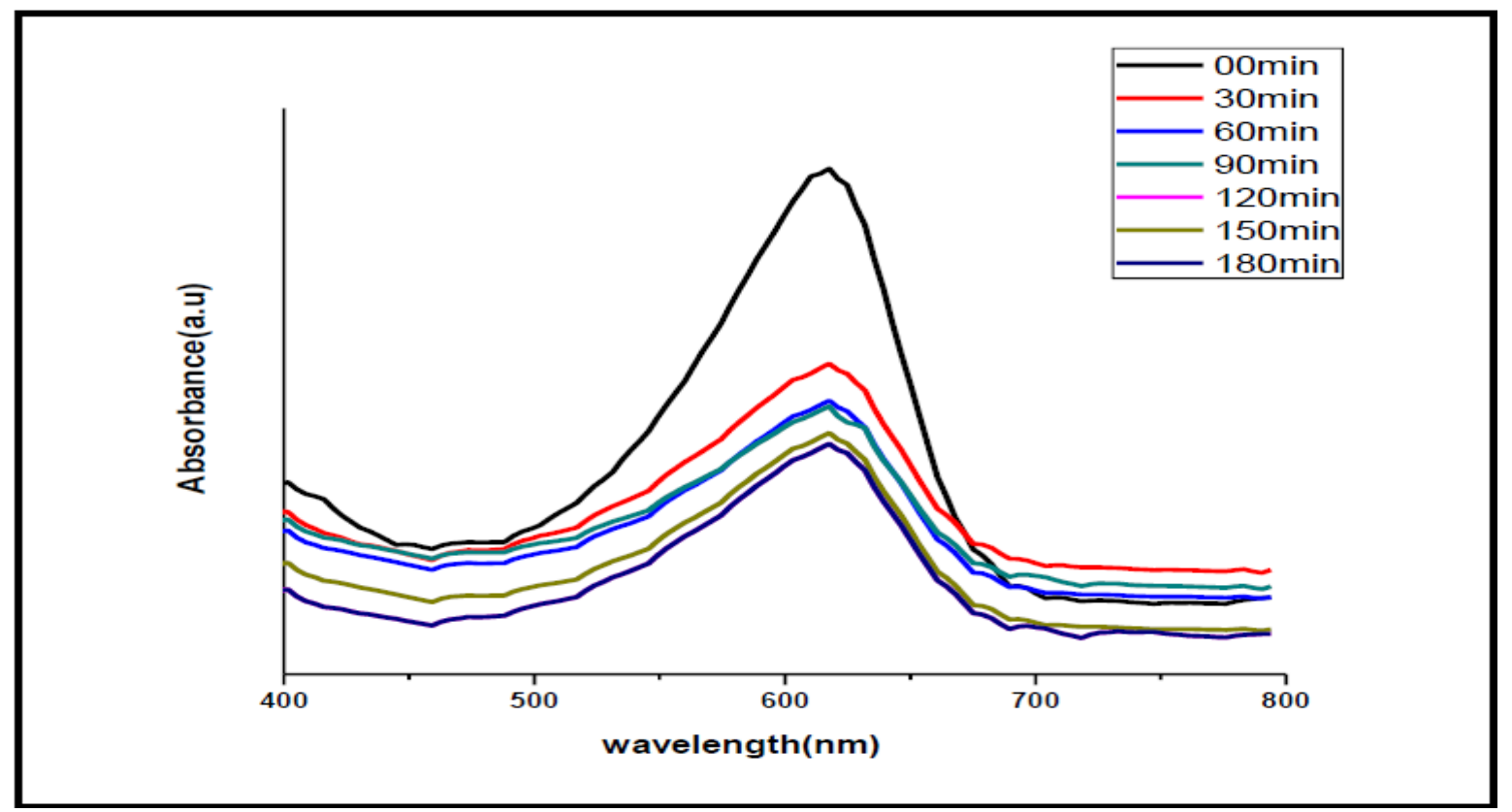

Fig. 8: UV-visible spectra of BTB degradation using LMO Catalyst

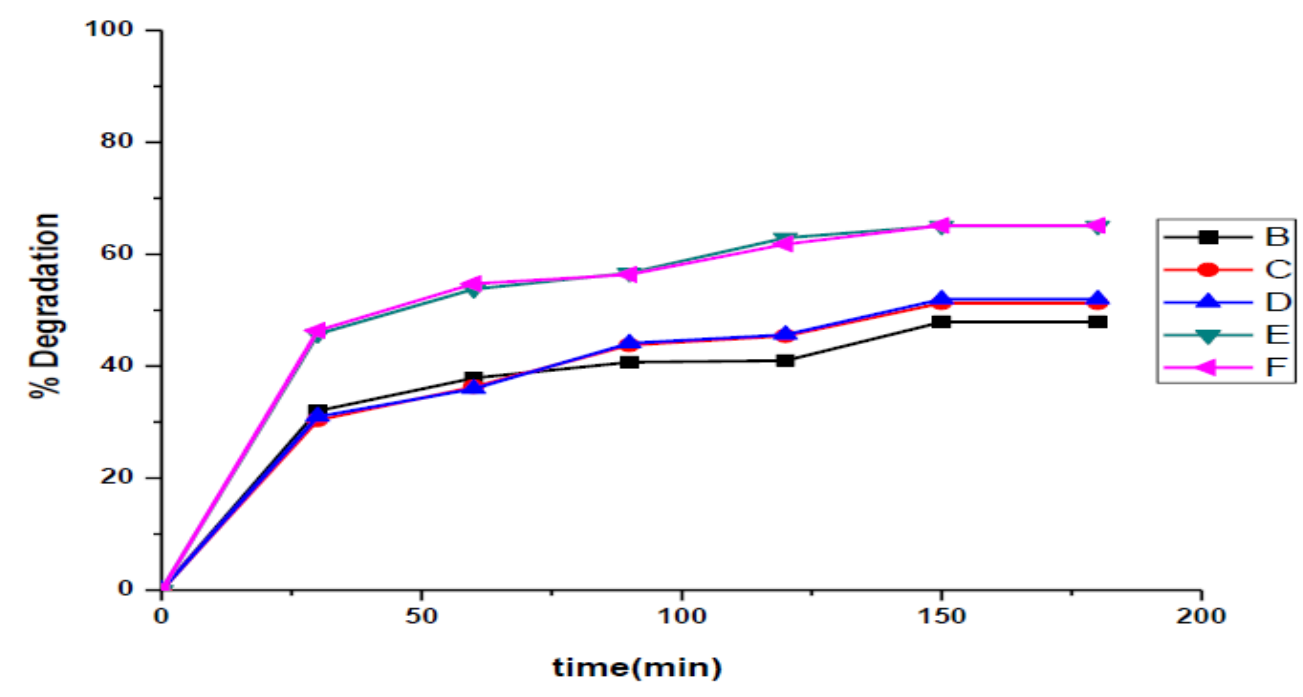

Fig. 9: Photodegradation of BTB using LMO catalyst B) 1\%LMO, C) 5\%LMO, D) 10\%LMO, E) 15\%LMO, F) $20 \% \mathrm{LMO}$

\section{CONCLUSION}

Different concentrations of LMO catalyst were synthesized by using sol gel method. The analytical methods were used to confirm the diverse physical and chemical natures of these catalysts. XRD of as synthesized LMO catalyst are made up of the cubic crystalline phase with high active surface area. The surface morphology and size investigation were performed with FESEM. In this present investigation, the dye decomposition rate for all five concentrations of LMO catalyst was superior for MO than BTB. 20 wt \% LMO possess more active surface area leads to higher photocatalytic efficiency (88.22\%) for Methyl Orange than the Bromothymol Blue (65.13\%).

\section{Conflict of interest}

None declared 


\section{REFERENCES}

1. Walker GM, Hansen L, Hanna JA, et al. J. Water Res. 2003; 37:2081-2089.

2. Pavan F A, Dias SLP, Lima EC, Benvenutti EV. Dyes Pigm., 2008; 76:64-69.

3. Kadirvelu K, Karthika C, Vennilamani N, Pattabhi S. Chemosphere., 2005; 60:1009-1017.

4. Malik PK. J.Hazard.Mater., 2004; 113:81-88.

5. Acero JL, Haderlein SB, Schmidt TC, Suter MJF, U Von Gunten. Environ. Sci. Technol., 2001; 35:42524259.

6. Iqbal MZ, Abdala AA. Thermally RSC Adv., 2013; 3:24455-24464.

7. Gupta VK, Agarwal S, Saleh TA. J. Hazard. 14 Mater., 2011; 185:17-23.

8. Rafatullah M, Sulaiman O, Hashim R, Ahmad A. J. Hazard. Mater., 2010; 177:70-80.

9. Al Bastaki. N. Chem. Eng. Process. Proc. Intens., 2004; 43:1561-1567.

10. Moghaddam SS, Moghaddam MR, Arami M. J. Hazard.Mater., 2010; 175:651-657.

11. Lee JW, Choi SP, Thiruvenkatachari R, Shim WG, Moon H. Dyes Pigm., 2006; 69:196-203.

12. Fincur NL, Krstic JB, Sibul FS, Sojic DV, Despotovic VN, Banic ND, et al. Chem. Eng. J., 2017; 307:1105-1115.

13. Verbruggen SW.J. Photochem. Photobiol. C 29 Photochem. Rev., 2015; 24:64-82.

14. Mazille F, Schoettl T, Pulgarin C. Appl. Catal. 31 B. Environ., 2009; 89:635-644.

15. Sathishkumar P, Anandan S, Maruthamuthu P, Swaminathan T, Zhou M, Ashokkumar M. Colloids Surf. A., 2011; 375:231-236.

16. Colon G, Maicu M, Hidalgo MC. J.A. Navio, 36 Appl. Catal. B. Environ., 2006, 67, 41-51.

17. Klosek S, Raftery D. J. Phys. Chem. B, 2001; 105:2815-2819.
18. Liu B, Wang X, Cai G, Wen L, Song Y, Zhao X. J. Hazard. Mater., 2009; 169:1112-1118.

19. Hamal DB, Klabunde KJ. J. Phys. Chem. C., 2011; 115:17359-17367.

20. Stengl V, Bakardjieva S. J. Phys. Chem. C., 2010; 44 114:19308-19317.

21. Deng QR, Xia XH, Guo ML, Gao Y, Shao G. Mater. Lett., 2011; 65:2051-2054.

22. Ranjit KT, Willner I, Bossmann SH, Braun AM. J. Catal., 2001; 204:305.

23. Ranjit KT, Willner I, Bossmann SH, Braun AM. En Viron. Sci. Technol., 2001; 35:1544.

24. Meksi M, Turki A, Kochkar H, Bousselmi L, GuillardC, Berhault G, AppliedCatalysis B:Environmental., 2016; 181:651-660.

25. Zhang Q, Fu Y, Wu Y, Zuo T. European Journal of Inorganic Chemistry, 2016; 11:1706-1711.

26. Yao L, Chen Z, Li J, et al. Journal of Molecular Liquids, 2020; 319:47-59.

27. Talebi R, Nasiri M, Rahnamaeiyan S. Journal of Materials ScienceMaterials in Electronics, 2015; 27(2):1500-1506.

28. X Lin et al. Materials Science and Engineering B., 2013; 178:520-526.

29. Ramezanalizadeh H, Peymanfar R, Khodamoradipoor N. Optik., 2018; 66.

30. Zhang J, Liu Z. Ceramics International., 2019; 45:10342-10347.

31. Nguyen LT, Nguyen LTH, Duong ATT, Nguyen BD, QuangHai N, et al. Materials.,2019; 12(8):1195.

32. Seisenbaeva GA, Sundberg $M$, Nygren $M$, Dubrovinsky L, Kessler VG. Mater. Chem. Phys., 2004; 87:142-148.

33. Zhong ZY, Mastai Y, Salkar RA, Koltypin Y, Gedanken A. Journal of Materials Research, 2000; 15(2):393-401. 